POLICY

\section{Carbon policy and innovation}

Am. Econ. J. Econ. Policy http://doi.org/jqc (2012)

Costly carbon emissions should stimulate innovation in environmentally friendly technologies. Yet, little research is available about the effects of carbon policy on privately funded technical innovation.

With a general equilibrium model, Joshua Gans of the University of Toronto, Canada, looks at three different types of innovation: fossil-fuel-efficient technologies (for example, a fuel-efficient car), alternativeenergy technologies (for example, solar panels) and carbon-offset technologies (such as carbon capture and storage). He finds that, under strict emission caps, fossil-fuel use will decrease and so will the incentive to invest in fossil-fuel-efficient innovation. In this scenario, alternative-energy technologies could attract investors; however, the incentive to innovate will largely depend on the profits, which are tied to the size of the economy, and stricter emission caps are likely to shrink the economy. If instead policy rewards carbon offsetting, reduced emissions will increase the price of carbon and make offset technologies unambiguously more lucrative.

\section{SCIENTIFIC COMMUNITY}

\section{Experts' knowledge assessed Climatic Change http://doi.org/jp8 (2012)}

Expert elicitation studies are a frequently used way of assessing scientific knowledge about future climate change. The approach is designed to incorporate experts' understanding of known flaws in computer models to provide a more comprehensive picture of uncertainty than model-driven methods can achieve. In practical terms the goal of expert elicitation is to determine experts' subjective probabilities for the values of key climate variables; making the implicit assumption that experts' knowledge can be captured in this way. However, decision theory has demonstrated this is not necessarily the case when information is ambiguous.

Using a choice experiment, Antony Millner from the Department of Agricultural and Resource Economics, University of California, Berkeley, US, and co-workers empirically determined whether experts' knowledge about climate sensitivity (the surface warming that results from a doubling of atmospheric $\mathrm{CO}_{2}$ ) can be captured by subjective probabilities. They found that a proportion of the participating climate scientists violated the criteria that must be satisfied for subjective probabilities to adequately describe their beliefs.

These results suggest that existing elicitation studies may qualitatively understate the extent of experts' uncertainty about climate change.

\section{FOREST CONSERVATION}

\section{Failed protection regimes}

Forest Policy Econ. http://doi.org/jqf (2012)

Countries rich in forests have established protected areas to conserve and manage forest resources. In sub-Saharan Africa, however, deforestation has continued despite conservation efforts raising questions about the usefulness of such interventions.

Jon Geir Petursson of the Norwegian University of Life Sciences, Ås, Norway and colleagues analyse the case of Mount Elgon, straddling the Uganda-Kenya border. With the help of satellite imagery, they found that since 1973 about a third of all forests within the protected areas on Elgon have been cleared in successive processes. Their analysis revealed the existence of complex political and institutional factors inside the formal protected regimes - including insurgencies, state disintegration, human resettlements and associated social conflicts - that acted as drivers of forest loss.

The researchers argue that policies to counter deforestation using a protected-area model can only work if understood in the broader institutional, social and political context, originating both inside and outside the official conservation regimes.

\section{OCEANOGRAPHY}

Heat distribution

J.Clim. http://doi.org/jqb (2012)

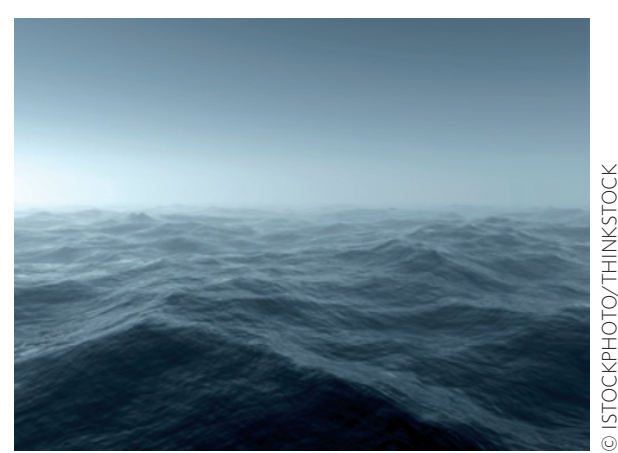

Increasing atmospheric greenhouse gases are projected to drive large changes in ocean circulation. The ocean currently reduces atmospheric warming through heat and carbon uptake, but the feedback of future circulation changes on global surface temperatures is not well understood.

Michael Winton of the Geophysical Fluid Dynamics Lab and National Ocean and Atmospheric Administration, Princeton, USA and co-workers used an earth system model to compare the effect of increased carbon dioxide, with and without changes in ocean circulation. Removing circulation changes results in a larger effect on ocean heat storage than on carbon storage. Reduced carbon uptake has a small impact on radiative forcing, while heat transport changes shift heat uptake to higher latitudes, increasing its cooling effect.

They find that changes in ocean circulation could significantly reduce surface warming, especially in the Northern Hemisphere. The circulation changes result in more globally distributed warming, with reduced warming at the subpolar latitudes and increased equatorial warming.

Written by Alastair Brown, Monica Contestabile and Bronwyn Wake. 